\title{
An alternatively spliced form of Met receptor is tumorigenic
}

\author{
Jae-Ho Lee ${ }^{1,2,4}$, Chong Feng Gao ${ }^{3}$, \\ Chong Chou Lee ${ }^{3}$, Myung Deok $\mathrm{Kim}^{1,2}$ and \\ George F. Vande Woude ${ }^{3}$ \\ ${ }^{1}$ Department of Biochemistry \\ School of Medicine \\ ${ }^{2}$ Department of Molecular Science and Technology \\ Graduate School, Ajou University \\ Suwon 443-721, Korea \\ ${ }^{3}$ Laboratory of Molecular Oncology \\ Van Andel Research Institute \\ Grand Rapids, MI 49503, USA \\ ${ }^{4}$ Corresponding author: Tel, 82-31-219-5053; \\ Fax, 82-31-219-5059; E-mail, jhlee64@ajou.ac.kr
}

Accepted 26 September 2006

Abbreviations: BCA, bicinchoninic acid; HGF/SF, hepatocyte growth factor/scatter factor

\begin{abstract}
The Met tyrosine kinase receptor is a widely expressed molecule, which mediates pleiotropic cellular responses following activation by its ligand, hepatocyte growth factor/scatter factor (HGF/SF). Previously, one of the authors identified an alternatively spliced form of Met (Met-SM) that lacked a single exon of a 47-amino-acid segment in the juxtamembrane domain. Here we report that Met-SM is a potent transforming gene in NIH3T3 mouse fibroblast cells. Met-SM-transfected NIH3T3 cells show stronger foci-forming activity than wild typeMet-transfected ones. In addition, Met-SM-transfected NIH3T3 cells form colonies in soft agar and are tumorigenic in athymic nu/nu mice. Furthermore, HGF/SF significantly increases the focus-forming activity of Met-SM comparing to wild type Met. The amount of protein and of tyrosine kinase activity of Met-SM accumulates to a high level following HGF/SF treatment. The accumulation of Met-SM correlated well with its delayed ubiquitination and increased stability. These results are consistent with the important role of the juxtamembrane domain in protein stability of Met receptor and suggest that the alternatively-spliced form may contribute to the development and progression of human cancer.
\end{abstract}

Keywords: alternative splicing; hepatocyte growth factor; neoplasms; proto-oncogene proteins c-met

\section{Introduction}

The Met tyrosine kinase is a high-affinity receptor for hepatocyte growth factor/scatter factor (HGF/SF) (Bottaro et al., 1991; Naldini et al., 1991). Both Met and HGF/SF are expressed in numerous tissues, although their expression is confined predominantly to cells of epithelial and mesenchymal origin, respectively (Stoker et al., 1987). Signaling via this receptor-ligand pair has been shown to affect a wide range of biological activities, including angiogenesis (Bussolino et al., 1992), cellular motility (Stoker et al., 1987), cell growth (Nakamura et al., 1986; Higashio et al., 1993), and morphogenic differentiation (Montesano et al., 1991; Tsarfaty et al., 1992).

In addition to mediating a variety of normal cellular processes, Met-HGF/SF signaling has been implicated in the development and progression of various malignant tumors (reviewed by Jeffers et al., 1996; Trusolino et al., 2002). Oncogenic form of Met includes the native receptor itself in an autocrine loop with its ligand HGF/SF (Bellusci et al., 1994; Rong et al., 1994). In addition to mediating transformation in model systems, there is evidence showing that autocrine Met-HGF/SF signaling plays a role in human cancer (reviewed by Jeffers et al., 1996). Met can be oncogenically activated via a number of specific point mutations. Mutations originally identified in human papillary renal carcinomas (Schmidt et al., 1997) were found to generate Met molecules possessing constitutive kinase activity and transforming ability (Jeffers et al., 1997a). In addition to papillary renal carcinoma, mutations in Met have been reported in ovarian cancer (Tanyi et al., 1999), in early-onset hepatocellular carcinoma (Park et al., 1999), gastric carcinoma (Lee et al., 2000) and in several cases they are found in metastatic lesion originated from the primary tumor (Otsuka et al., 1998; Di Renzo et al., 2000).

Whereas all the mutations reported in hereditary papillary renal cancer and hepatocellular carcinoma are missense mutations of the tyrosine kinase domain of Met, the missense mutation found in gastric carcinoma by the authors was located in the juxtamembrane domain and showed transforming activity when overexpressed in NIH 3T3 mouse fibroblasts (Lee et al., 2000). Along with the presence of a protein kinase $C$ (PKC) regulatory site (Gandino et al., 1994) and a protein tyrosine phosphatase-binding site in the juxtamembrane domain (Villa-Moruzzi et al., 1998), there was a clear demonstration of $\mathrm{Y} 1003$ as the target of $\mathrm{c}-\mathrm{Cbl}$ binding, 
which leads ubiquitination and protein degradation (Peschard et al., 2001). An activating mutation in the juxtamembrane in gastric cancer raised the question of biological properties of previously reported alternatively splicing form of Met (Met-SM) by one of the authors, which lacked exon 14 that encoded a significant portion of Met juxtamembrane domain (Lee et al., 1994). Here, we show that Met-SM was different biochemically from wild type Met and has enhanced oncogenic activity.

\section{Materials and Methods}

\section{Cell lines and reagents}

NIH 3T3 cells (CRL1658) were obtained from the American Type Culture Collection (ATCC) and cultured in DMEM (Life Technologies) supplemented with $10 \%$ calf serum (Life Technologies). These cells produce only two scatter units/ml of HGF/SF, which is significantly lower than other NIH 3T3 sublines we have analyzed (Lee et al., 2000).

\section{Plasmid and constructs}

The wild-type Met expression vector (PMB11) contains the murine Met cDNA in PMB1 vector as described previously (Lee et al., 2000). The Met-SM was subcloned from the original clone (Lee et al., 1994) into the same expression vector as wild type. To construct other Met mutants, the QuickChange site-directed mutagenesis kit (Stratagene) was used according to the manufacturer's instructions with PMB11 as the template. Mutations were verified by sequencing both strands of DNA in the region of interest.

\section{Transfection and focus-forming assay}

Transfections and focus-forming assays were performed as described previously (Lee et al., 2000). Half of the transfected cells were cultured in DMEM $/ 10 \%$ CS supplemented with $800 \mu \mathrm{g} / \mathrm{ml} \mathrm{G}-418$ (Life Technologies). These cells were used to assess the transfection efficiency and were grown as pools of cells consisting of at least 100 colonies and used for expression, phosphorylation, and in vitro and in vivo tumorigenesis experiments. Focus-forming activity assays were performed as described previously (Jeffers et al., 1997a).

\section{Soft agar colony generation assay}

Noble agar solution (3.5\% in PBS) prewarmed at $40^{\circ} \mathrm{C}$ was added to DMEM containing $10 \%$ FBS pre-warmed at $37{ }^{\circ} \mathrm{C}$ to make $0.7 \%$ agar. After rapid mixing by inversion, the resultant solution was added to 6 -well plates $(1 \mathrm{ml} /$ well). The cells reaching $70-80 \%$ confluence were trypsinized, washed with PBS three times and diluted in Noble agar solution (0.3\% Noble agar in DMEM with $10 \%$ FBS) at $37^{\circ} \mathrm{C}$. Then the cell suspensions were added into the 6 -well plate with $0.7 \%$ agar layer $(5000$ cells in $1 \mathrm{ml})$. Plates were incubated at $37^{\circ} \mathrm{C}$, with $5 \% \mathrm{CO}_{2}$ condition for three weeks. Twice a week, DMEM with $10 \%$ FBS with or without 100 units/ml HGF/SF were added $(1 \mathrm{ml} /$ well) to provide required nutrition and growth factors.

\section{Western blot analysis}

Western blot analysis was performed essentially as described (Baek et al., 2004) under reducing conditions using the following primary antibodies: rabbit anti-Met polyclonal antibody (SP260; Santa Cruz Biotechnology), anti-phosphotyrosine monoclonal antibody (clone 4G10; Upstate Biotechnologies Inc.), and anti-ubiquitin monoclonal antibody (clone 1B3; MBL).

\section{Immunoprecipitation}

Monolayers of stably transfected cells were washed twice with ice-cold PBS, lysed in ice-cold RIPA buffer consisting of $10 \mathrm{mM}$ sodium phosphate ( $\mathrm{pH} 7.2), 150$ $\mathrm{mM} \mathrm{NaCl}, 1 \%(\mathrm{~V} / \mathrm{V})$ Nonidet P-40, 0.1\% SDS supplemented with $10 \mathrm{mM}$ sodium fluoride, $5 \mathrm{mM}$ sodium orthovanadate, and complete protease inhibitor cocktail (Boehringer Mannheim). The cell lysates were centrifuged at $4^{\circ} \mathrm{C}$ for $15 \mathrm{~min}(14,000 \mathrm{~g})$ and the supernatants were collected for further analysis. When samples were supposed to be used for the analysis of ubiquitination, $N$-ethylmaleimide, an inhibitor of deubiquitinating enzyme, was added at a concentration of $20 \mathrm{mM}$. After quantitation by using BCA protein assay reagent (Pierce), $400 \mu \mathrm{g}$ of each lysate was precleared with protein A-Sepharose and then incubated with anti-Met antibody (SP260; Santa Cruz Biotechnology) and protein A-Sepharose for overnight at $4^{\circ} \mathrm{C}$ with rotation. The samples then were washed three times with ice-cold RIPA buffer. SDS gel-loading buffer (containing reducing agent) was added to each sample. After boiling for $5 \mathrm{~min}$ and centrifuging at $14,000 \mathrm{~g}$ for $5 \mathrm{~min}$, the resulting supernatants were resolved by SDS/PAGE and examined by Western blot analysis.

\section{Thymidine incorporation assay}

The thymidine incorporation assay was carried out as follows. Cells were plated in 96 -well plates $(2 \times$ $10^{3}$ cells/well) and cultured in DMEM supplemented with $10 \%$ CS for $24 \mathrm{~h}$. The cells were starved in serum-free DMEM medium for $30 \mathrm{~h}$ and then stimulated with various concentrations of HGF/SF for 
$12 \mathrm{~h}$. [Methyl- ${ }^{3} \mathrm{H}$ ]thymidine $(1 \mu \mathrm{Ci}$, Perkin-Elmer Life Science) was added $4 \mathrm{~h}$ before analysis. Thymidine incorporation into DNA was measured by cold $5 \%$ trichloroacetic acid precipitation, followed by extraction in lysis buffer $(0.02 \mathrm{~N} \mathrm{NaOH}, 0.1 \%$ SDS), and then counted in the ${ }^{3} \mathrm{H}$ channel of a liquid scintillation counter (TRI-CARB 3100TR, Packard).

\section{Pulse-chase analysis}

Cells were seeded at a density of $1 \times 10^{6}$ cells $/ 100-\mathrm{mm}$ dish in DMEM containing $10 \%$ calf serum. The next day, cells were cultured in serum-free DMEM in the presence or absence of HGF/SF (100 scatter units $/ \mathrm{ml}$ ) for $24 \mathrm{~h}$. Then the cells were rinsed twice in labeling medium (Life technologies, Inc) and incubated in serum-free labeling medium for $3 \mathrm{~h}$. The
A

WT

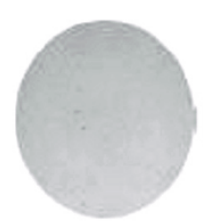

$\mathrm{Sm}$

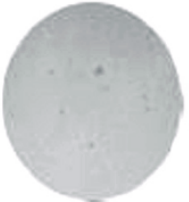

DNA ( $\mu$ g/plate) : $\quad 0.05$

B

WT
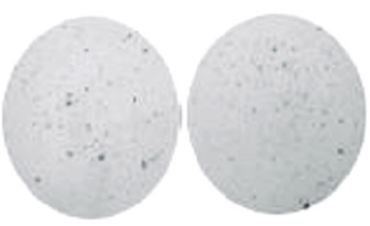

With exogenous HGF

Sm
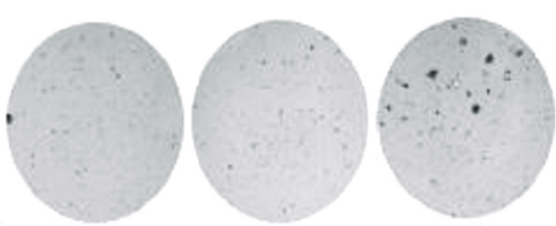

DNA ( $\mu \mathrm{g} /$ plate)

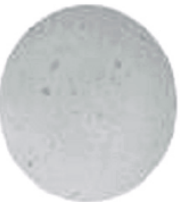

0.15
Without exogenous HGF
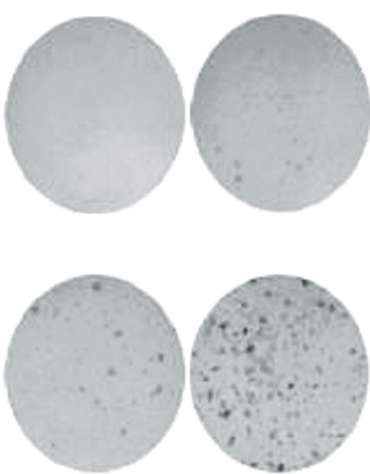

0.5

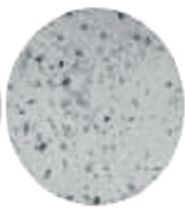

1.5

\section{Y-14,15FF}

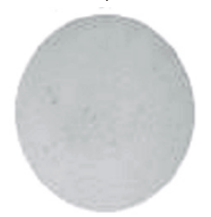

Y-14,15FF (Sm)

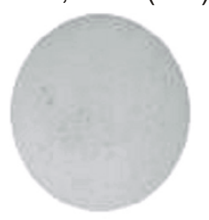

1.5

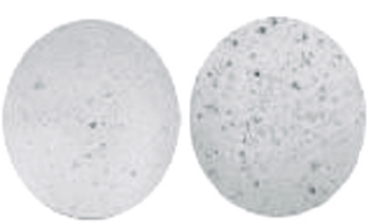

Y-14,15FF

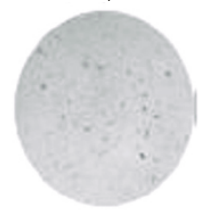

Y-14,15FF (Sm)

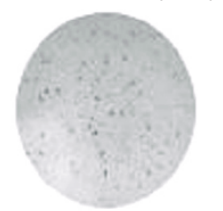

1.5

C

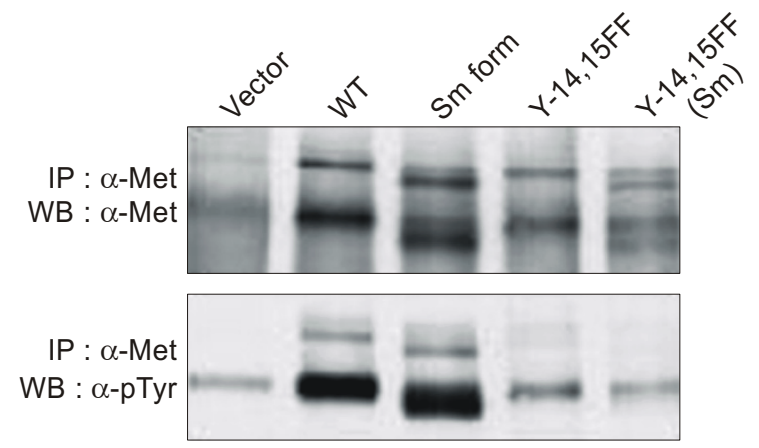

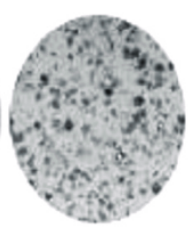

1.5
Figure 1. Differential foci induction by Met-WT and Met-SM. Cells transfected with indicated amounts of Met-WT (WT) or Met-SM (Sm) cDNA were assessed for focus-forming ability in the absence $(A)$ or presence (B) of HGF/SF (200 scatter units $/ \mathrm{ml})$. Cells transfected with $1.5 \mu \mathrm{g}$ DNA/plate of $Y 14,15-\mathrm{FF}$ mutant of Met-WT (Y14,15-FF) or Y14,15-FF mutant of Met-SM (Y14,15-FF (Sm)) were also assessed for focus-forming ability. (C) Immunoprecipitation followed by Western blot analysis was performed to assess the protein amount and tyrosine phosphorylation of Met-WT and Met-SM transfected cells. Representative results are shown from independent experiments performed three times $(A, B)$. 
cells were pulsed in $0.2 \mathrm{mCi}^{35} \mathrm{~S}$-labeled methionine and cysteine $(0.2 \mathrm{mCi} / \mathrm{ml} ; \mathrm{ICN})$ in the presence or absence of exogenous HGF/SF (100 scatter units/ml). After $1 \mathrm{~h}$, the cells were washed with DMEM and cultured in DMEM containing $3 \mathrm{mg} / \mathrm{ml}$ methionine. At different time points, the cells were lysed and used for immunoprecipitation with anti-Met antibody. Precipitated proteins were resolved by $8 \%$ Tris-glycine gel electrophoresis, and the resulting gels were used for autoradiography.

\section{In vivo tumorigenecity assay}

Pools of G418-resistant NIH 3T3 cells expressing the indicated Met proteins were generated as described above and were shown to express nearly equal amount of exogenous Met before use. The cells were plated as described, and $5 \times 10^{5}$ cells were inoculated subcutaneously into 4-week-old female athymic nude mice.

Table 1. Nude mouse tumorigenesis

\begin{tabular}{lcc}
\hline Met construct & $\begin{array}{c}\text { No. mice with tumors/ } \\
\text { No. mice injected }\end{array}$ & $\begin{array}{c}\text { Mean tumor size, } \\
\mathrm{mm}^{2} \text { (mean } \pm \text { S.D.) }\end{array}$ \\
\hline WT & $0 / 6^{\mathrm{c}}$ & 0 \\
SM & $6 / 6(10)$ & $57.8 \pm 9.1$ \\
Y-14,15 FF (WT) & $0 / 6$ & 0 \\
Y-14,15 FF (SM) & $0 / 6$ & 0 \\
\hline
\end{tabular}

${ }^{a}$ Number of mice with tumors 18 day after inoculation of $5 \times 10^{5}$ cells; (days post-inoculation when tumors were first detected in each animal). ${ }^{b}$ Size at 18 day after injection (subsequently, all mice with tumor burden were sacrificed). 'At 25 day, the first mouse developed a palpable tumor.

\section{A}

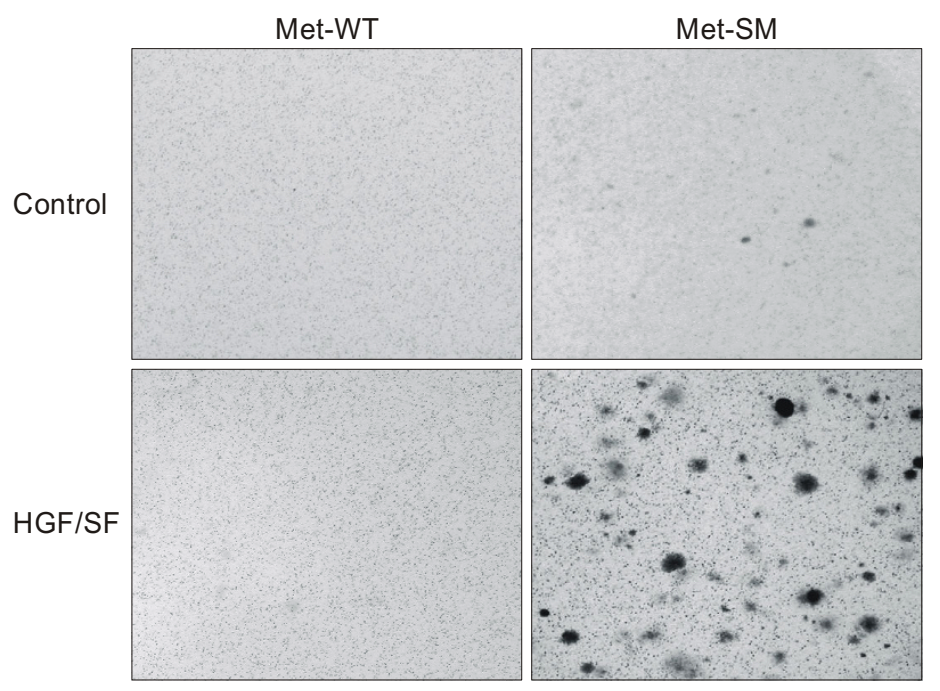

B

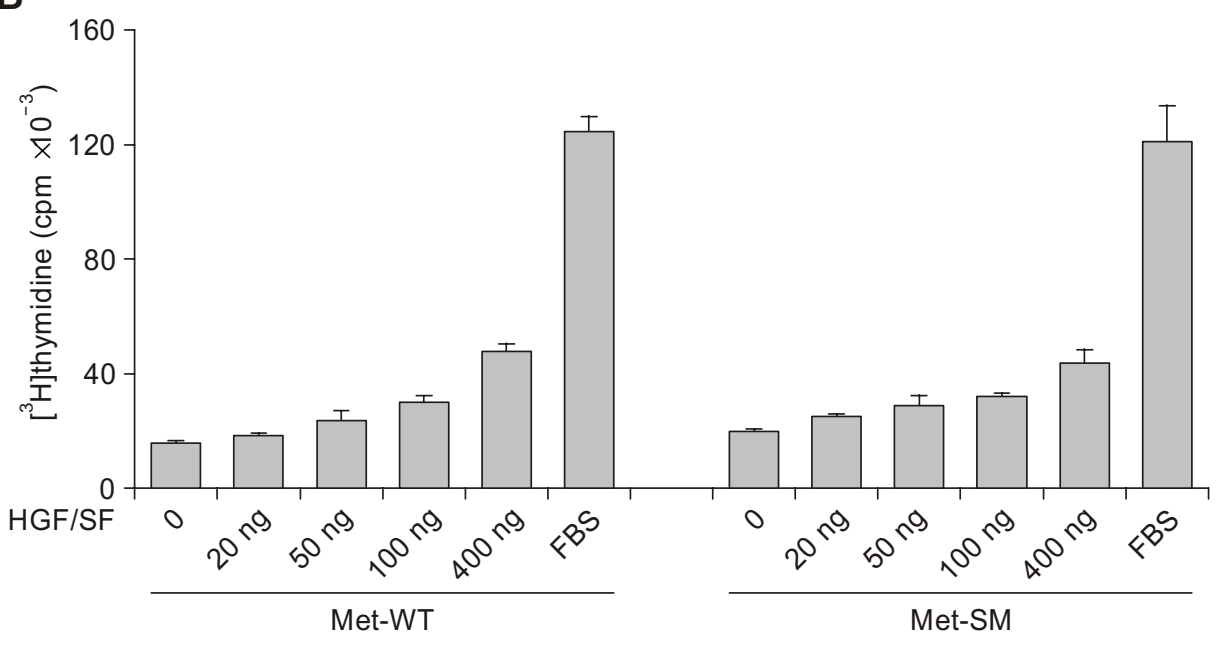

Figure 2. Anchorage-independent growth of NIH $3 \mathrm{~T} 3$ cells transfected with Met-SM. (A) NIH 3T3 cells transfected with indicated vectors were diluted in $0.3 \%$ Noble agar solution $(0.3 \%$ Noble agar in DMEM with $10 \%$ FBS) and added into each well (5000 cells in $1 \mathrm{ml}$ ) with pre-formed $0.7 \%$ agar layer containing DMEM with $10 \%$ FBS. Plates were incubated at $37^{\circ} \mathrm{C}$, with $5 \% \mathrm{CO}_{2}$ condition for three weeks. Twice a week, DMEM containing 10\% FBS with (HGF/SF) or without HGF/SF (Control) were added $(1 \mathrm{ml} / \mathrm{well}$ ) to provide required nutrition and growth factors. The pictures of colonies were taken after crystal violet staining. Representative fields of view from three independent experiments are shown. (B) HGF/SF-induced cell proliferation was assessed by thymidine incorporation assay as described under Materials and Methods. 


\section{Results}

\section{Enhanced tumorigenecity by Met-SM}

To address the biological activity of Met-SM, we transfected NIH 3T3 cells with different amounts of wild type Met (Met-WT) or Met-SM expressing vector. The cells were maintained in DMEM containing 800 $\mu \mathrm{g} / \mathrm{ml} \mathrm{G}-418$ for $12 \mathrm{~d}$ and stained with crystal violet. Whereas the wild type produced few foci even at a concentration of $1.5 \mu \mathrm{g}$ DNA per plate, Met-SM produced more foci with less DNA in a dosedependent manner (Figure 1A), showing the Met-SM was truly transforming. To address the effect of exogenous HGF/SF in the transforming activity of Met-SM, the ligand was added to the culture at a concentration of 200 scatter units $/ \mathrm{ml}$ every 2-3 d. Exogenous HGF/SF clearly increased the number and size of foci both with Met-WT and Met-SM, and the extent of the increase was far more significant with Met-SM (Figure 1B). Both the expression level and the phosphotyrosine level were comparable between Met-WT and Met-SM (Figure 1C). As another in vitro method to test the transforming activity, a soft agar colony generation assay was performed. The results showed that only Met-SM transfected $\mathrm{NIH}$ 3T3 cells formed large colonies in soft agar, although HGF/SF-induced proliferation rate was comparable (Figure 2A and B). More importantly, when these cells were used for in vivo tumorigenesis assay in nude mice, Met-SM was highly tumorigenic based on both the number of mice with tumors and the size of the tumors developed (Table 1).

Y14, 15 (the $14^{\text {th }}$ and $15^{\text {th }}$ Tyr residues in cytosolic portion of Met) form a common docking site for several different signaling molecules downstream of Met. The Y14, 15 mutants of Met-WT are known to block Met signaling and were used as controls. Met-WT and Met-SM mutants Y14, 15-FF molecules were transfected into NIH 3T3 cells and compared to Met-WT and Met-SM. The transforming capacity of Met-SM observed in a focus-formation assay and an in vivo nude mice assay were abolished by the introduction of Y14, 15-FF mutation (Figrue 1 and Table 1). These data indicate that the transforming signaling from Met-SM is mediated through the $\mathrm{Y} 14$, 15 docking site as Met-WT.

\section{Impaired down-regulation of Met-SM by HGF/SF}

To study the mechanism responsible for the biological activity of Met-SM, we pooled colonies of either Met-WT or Met-SM-transfected NIH 3T3 cells for biochemical analysis. We first detected Met protein tyrosine phosphorylation in response to HGF/SF. In the absence of exogenous HGF/SF, Met phosphotyrosine was not significantly different between
Met-WT and Met-SM (Figure 1C and 3, top panel). However, in the presence of exogenous HGF/SF, Met-WT phosphotyrosine was the highest at one hour, then decreased. By contrast, Met-SM phosphorylation was greater than Met-WT at each time and dramatically increased even to 24 hours. When the same blot was stripped and probed for Met, it turned out that the striking difference in phosphotyrosine at least partly resulted from the difference in the amounts of Met protein (Figure 3, second panel from the top). After HGF/SF treatment, the amount of Met-WT decreased, while that of Met-SM increased and was maximum at $24 \mathrm{~h}$. The difference in phosphotyrosine and c-Met protein was also observed in whole cell lysates by Western blot analysis (Figure 3, the third and fourth panel from the top). In both panels, the level of Met-SM phosphorylation and Met protein p140 increased dramatically over 24 hours. Since the cDNAs of the two forms of Met are

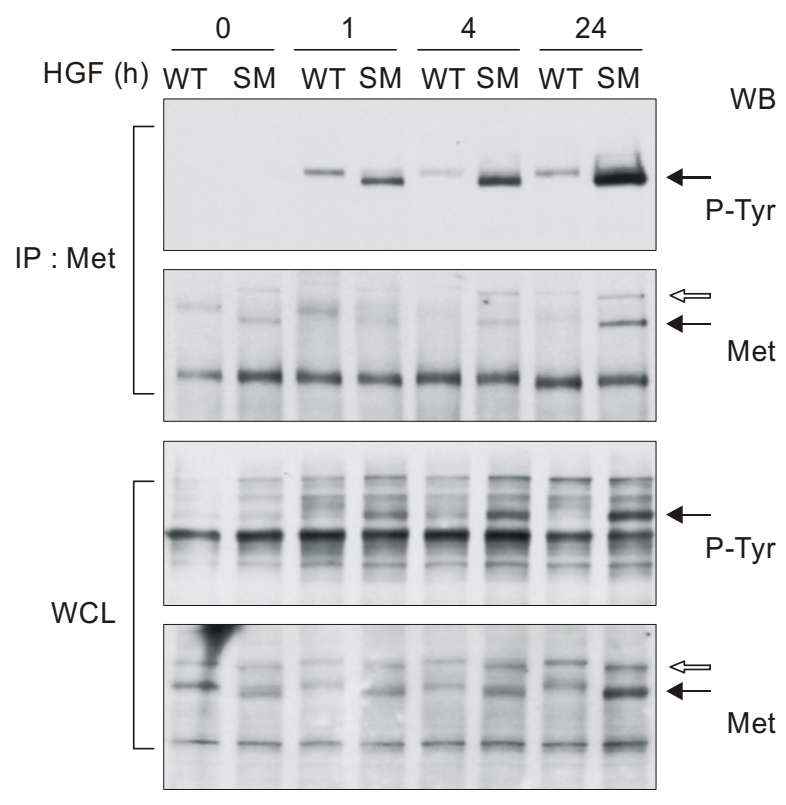

Figure 3. Accumulation of the protein amount and phosphorylation of Met-SM upon HGF/SF treatment. Cells stably transfected with vectors expressing Met-WT (WT) or Met-SM (SM) were cultured in DMEM/10\% CS to confluency of $40-50 \%$. HGF/SF (200 scatter units $/ \mathrm{ml}$ ) was added to each dish at various time points before the harvest as indicated $(0$, 1,4 , and $24 \mathrm{~h}$ ). Four hundred $\mu \mathrm{g}$ of cell lysate was immunoprecipitated with anti-Met antibody (SP260). The precipitate (IP: $\alpha-M e t)$ was resolved on an $8 \%$ gel, and analyzed by Western blot analysis using anti-phosphotyrosine antibody ( $\alpha$-P-Tyr, top panel) or anti-Met antibody $(\alpha-$ Met, second panel from the top). Forty $\mu \mathrm{g}$ of whole cell lysate (WCL) was resolved on an $8 \%$ gel and examined by Western blot analysis using anti-phosphotyrosine antibody ( $\alpha$-P-Tyr, third panel from the top). The filters were stripped and reprobed with anti-Met antibody ( $\alpha$-Met, bottom panel). Blank and filled arrows denote the $170 \mathrm{kDa}$ single chain precursor of Met and the $140 \mathrm{kDa} \beta$-chain of the mature Met heterodimer, respectively. 
A
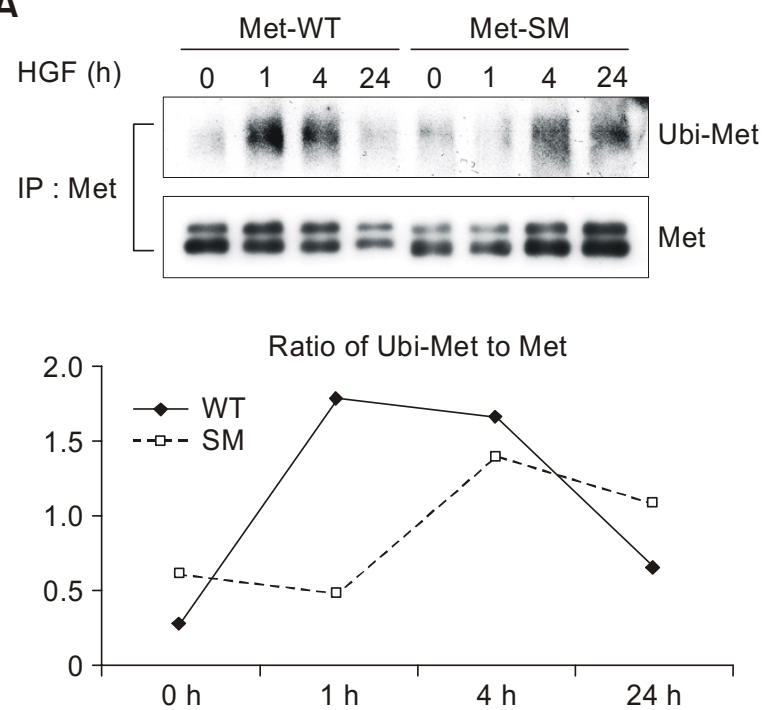

B

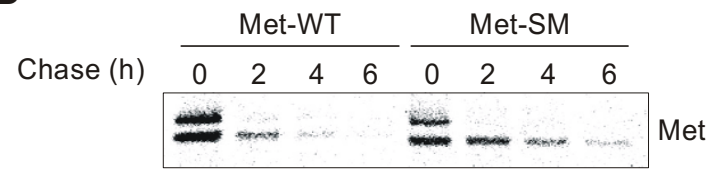

Figure 4. Enhanced stability of Met-SM. (A) Delayed ubiquitination of Met-SM protein. NIH 3T3 cells stably expressing Met-WT or Met-SM were serum-starved for $12 \mathrm{~h}$, and then treated with HGF/SF (100 scatter unit/ml) for indicated times. Cells were washed with ice-cold PBS and lysed in ice-cold RIPA buffer. Five hundred microgram of each lysate was immunoprecipitated with anti-Met antibody. Precipitated proteins were resolved on an $8 \%$ gel and probed with anti-ubiquitin antibody. The ratio of ubiquitinated Met to total precipitated Met based on the band intensity in $(A)$ was measured by Sion image analysis software. (B). HGF/SF-induced receptor down-regulation of Met-SM is impaired. NIH 3T3 cells stably expressing Met-WT or Met-SM were cultured in serum free medium containing HGF/SF (100 scatter unit/ml) for $24 \mathrm{~h}$. Then the cells were pulse-labeled with $\left.{ }^{35} \mathrm{~S}\right]$ Trans label mix $(0.2 \mathrm{mCi} / \mathrm{ml})$ and chased for the indicated hours under the continuing presence of exogenous HGF/SF (100 scatter unit/ml).

in the same construct and since there was no difference in the amount of Met proteins in the absence of HGF/SF, it is highly unlikely that this difference in the amount of protein resulted from the difference in the rate of de novo protein synthesis.

Ubiquitination is required for ligand-induced degradation of Met (Jeffers et al., 1997b). We therefore, examined the ubiquitination of Met-WT and Met-SM upon HGF/SF treatment. The NIH 3T3 clones expressing Met-WT and Met-SM were treated with HGF/SF for different times. Met protein was immunoprecipitated from cell lysates and the ubiquitinated Met was detected by Western blot analysis with antiubiquitin antibody. HGF/SF induced rapid and strong ubiquitination of Met-WT, whereas the ubiquitination of Met-SM was significantly delayed (Figure 4A).

To examine whether the delayed ubiquitination of Met-SM was associated with increased stability, we performed pulse-chase analysis. After $1 \mathrm{~h}$ of pulse labeling, two bands with molecular weights of 170 $\mathrm{kDa}$ and $140 \mathrm{kDa}$ respectively were detected. The $140 \mathrm{kDa}$ band is the mature form of Met derived from the $170 \mathrm{kDa}$ precursor form. Following pulsechase analysis, in the presence of HGF/SF, Met-SM showed decreased degradation when compared with Met-WT (Figure 4B). Taken together, the accumulation of SM-Met resulted at least partially from decreased degradation possibly caused by the delay in the ligand-induced ubiquitination of Met.

\section{Discussion}

One of the authors previously identified an HGF/SF receptor isoform (Met-SM form) that has a deletion of 47 amino acids in the juxtamembrane domain, apparently by RNA splicing (Lee et al., 1994). The differential splicing and its resultant protein occur in a variety of mouse tissues, suggesting the biological significance of this isoform. We have tried to find Met-SM in rat tissues and human tissues by RT-PCR. While the Met-SM was present in various tissues from rat, it was not observable from any human normal tissues tested (unpublished observation by J.H. Lee). Multiple reasons may contribute to the different expression of Met-SM in normal tissue between murine and human (reviewed by Lopez et al., 1998). In spite of the difference in the expression in normal tissue, its strong oncogenic activity shown in this study suggests its potential role in human cancer. Recently, some researchers claimed to find Met-SM from a primary human lung cancer sample (Ma et al., 2005), strongly suggesting possible involvement of this alternative splicing form in human tumorigenesis.

The role of the juxtamembrane region of Met in cell transformation is relatively unknown. It was reported that the addition of the juxtamembrane domain to TPR-Met fusion protein abolished the transforming activity of TPR-Met (Vigna et al., 1999), suggesting this domain has inhibitory effect on the transforming activity of activated Met. Actually, the part of juxtamembrane domain deleted in Met-SM was believed to act as regulatory sites of the enzymatic activity of Met. Specifically, two sites have been described as regulatory sites. Ser985 (Ser983 in mouse Met, accession number: NP032617, NCBI) was described as a substrate of PKC, and its phosphorylation by $\mathrm{PKC}$ results in the downregulation of tyrosine kinase activity of Met (Gandino et al., 1994). In addition, it was reported that a specific protein tyrosine phosphatase, PTP-S, binds to this region 
and acts as a down-regulation mechanism after the activation of Met receptor by its ligand (Villa-Moruzzi et al., 1998). The remarkable difference in tyrosine phosphorylation level between two forms after adding HGF/SF strongly suggests the difference in downregulation mechanism.

There were some reports showing the involvement of a RING-finger protein $\mathrm{c}-\mathrm{Cbl}$ in the degradation of c-Met protein by ubiquitination (Peschard et al., 2001; Taher et al., 2002). They showed that the tyrosine residue Y1003 (Y1001 in mouse Met, accession number: NP032617, NCBI) in the juxtamembrane domain is essential for the binding of $\mathrm{c}-\mathrm{Cbl}$ to Met. Since Y1003 resides in the exon-14 coding region, it was highly probable that Met-SM is less ubiquitinated than Met-WT. Consistent with these reports, we detected a significantly delayed ubiquitination of Met-SM in response to HGF/SF treatment relative to that of Met-WT. The delayed ubiquitination of Met-SM correlated with its enhanced stability as revealed by pulse-chase analysis, suggesting that differences in the protein degradation pathway may responsible for the enhanced oncogenic activity.

Although the NIH 3T3 cells used in this study secrete two scatter units/ml of HGF/SF (data not shown), this secretion didn't affect much in terms of the amount of tyrosine phosphorylation (see Figure 1). However, the difference in the focus-forming assay was significant between the two Met forms even in the absence of exogenous HGF, suggesting possible qualitative differences in the downstream signaling. One of the authors showed the differential induction of three tyrosine-phosphorylated proteins by the receptor isoforms in COS-7 cells, suggesting that the juxtamembrane domain of Met plays a role in selective signal transduction (Lee et al., 1995). Furthermore, the p85 subunit of phosphatidylinositol3-OH kinase (PI3 kinase) co-precipitated with the small isoform of the HGF/SF receptor, suggesting that the juxtamembrane region plays a role in negative regulation of the binding of $\mathrm{PI} 3$ kinase to the HGF/SF receptor (Lee et al., 1995). Multiple cellular responses are regulated by $\mathrm{PI} 3 \mathrm{~K}$, including cell growth, inhibition of apoptosis, actin cytoskeleton reorganization, vesicle transport, and cellular transformation (reviewed by Cantley et al., 2002). Moreover, PI3K activity is reported to be critical for Met-mediated cell migration, in vitro tubulogenesis (Derman et al., 1995), and resistance to apoptotic agents in MDA-MB-453 cells and in glioma cell lines (Bowers et al., 2000; Fan et al., 2000). The majority of activated PI3K downstream from the Met receptor is associated with the multisubstrate adaptor protein Gab-1 (Furge et al., 2000), whose recruitment and phosphorylation requires $\mathrm{Y} 15$ and, to a lesser extent, Y14 (Nguyen et al., 1997). Consistent with this, the
Y14, 15FF mutation abolished the transforming activity of Met-SM in both the absence and presence of HGF/SF. However, since Y14, 15 is known to be a docking site for several downstream signaling molecules such as PLC-r, pp60-Src, and Grb-2 (Lee et al., 1995), we can not exclude the possible involvement of other signaling molecules in the transforming activity of Met-SM.

In this paper, we have shown the transforming activity of Met-SM, a natural isoform of Met receptor produced by alternative splicing. This strongly suggests the possibility of the role of Met-SM in tumorigenesis by HGF/SF-Met signaling. It would be very interesting to explore the role of Met-SM in different human cancers reported to show enhanced HGF-Met signaling. Moreover, since this alternative splicing form presents in normal tissues from as early as the day-9 fetus of mice (Lee et al., 1994), it may also play a role during normal mouse development.

\section{Acknowledgement}

We thank Lingmei Wang for helpful comments throughout this study; Linda Miller and YanLi Su for technical assistance; David Nadziejka and Yun-yeon Park for editorial support. This work was supported by Grant No. KRF-2001-E00010(RO2-2001-00500) from Korea Research Foundation and by Grant No. R13-2003-019 from Korea Science and Engineering Foundation.

\section{References}

Baek CM, Jeon SH, Jang JJ, Lee BS, Lee JH. Transforming variant of Met receptor confers serum independence and anti-apoptotic property and could be involved in the mouse thymic lymphomagenesis. Exp Mol Med 2004;36;283-91

Bellusci S, Moens G, Gaudino G, Comoglio P, Nakamura T, Thiery JP, Jouanneau J. Creation of an hepatocyte growth factor/scatter factor autocrine loop in carcinoma cells induces invasive properties associated with increased tumorigenicity. Oncogene 1994;9:1091-99

Bottaro DP, Rubin JS, Faletto DL, Chan AM, Kmiecik TE, Vande Woude GF, Aaronson SA. Identification of the hepatocyte growth factor receptor as the c-met proto-oncogene product. Science 1991;251:802-4

Bowers DC, Fan S, Walter KA, Abounader R, Williams JA, Rosen EM, Laterra J. Scatter factor/hepatocyte growth factor protects against cytotoxic death in human glioblastoma via phosphatidylinositol 3-kinase- and AKT-dependent pathways. Cancer Res 2000;60:4277-83

Bussolino F, Di Renzo MF, Ziche M, Bocchietto E, Olivero M, Naldini, L, Gaudino G, Tamagnone L, Coffer A, Comoglio PM. Hepatocyte growth factor is a potent angiogenic factor which stimulates endothelial cell motility and growth. J Cell Biol 


\section{2;119:629-41}

Cantley LC. The phosphoinositide 3-kinase pathway. Science 2002;296:1655-7

Derman MP, Cunha MJ, Barros EJ, Nigam SK, Cantley LG. HGF-mediated chemotaxis and tubulogenesis require activation of the phosphatidylinositol 3-kinase. Am J Physiol 1995;268:F1211-7.

Di Renzo MF, Olivero M, Martone T, Maffe A, Maggiora P, Stefani AD, Valente G, Giordano S, Cortesina G, Comoglio PM. Somatic mutations of the MET oncogene are selected during metastatic spread of human HNSC carcinomas. Oncogene 2000;19:1547-55

Fan S, Ma YX, Wang JA, Yuan R.Q, Meng Q, Laterra JJ, Goldberg ID, Rosen EM. The cytokine hepatocyte growth factor/scatter factor inhibits apoptosis and enhances DNA repair by a common mechanism involving signaling through phosphatidyl inositol 3' kinase. Oncogene 2000;19:2212-23

Furge KA, Zhang YW, Vande Woude GF. Met receptor tyrosine kinase: enhanced signaling through adapter proteins. Oncogene 2000;19:5582-9

Gandino L, Longati P, Medico E, Prat M, Comoglio PM. Phosphorylation of serine 985 negatively regulates the hepatocyte growth factor receptor kinase. J Biol Chem 1994; 269:1815-20

Higashio K, Shima N. Tumor cytotoxic activity of HGF-SF. EXS 1993;65:351-68

Jeffers M, Rong S, Vande Woude GF. Enhanced tumorigenicity and invasion-metastasis by hepatocyte growth factor/ scatter factor-met signalling in human cells concomitant with induction of the urokinase proteolysis network. Mol Cell Biol 1996;16:1115-25

Jeffers M, Schmidt L, Nakaigawa N, Webb CP, Weirich G, Kishida T, Zbar B, Vande Woude GF. Activating mutations for the met tyrosine kinase receptor in human cancer. Proc Natl Acad Sci USA 1997a;94:11445-50

Jeffers M, Taylor GA, Weidner KM, Omura S, Vande Woude GF. Degradation of the Met tyrosine kinase receptor by the ubiquitin-proteasome pathway. Mol Cell Biol 1997b;17:799808

Lee CC, Yamada K. Identification of a novel type of alternative splicing of a tyrosine kinase receptor. Juxtamembrane deletion of the c-met protein kinase $\mathrm{C}$ serine phosphorylation regulatory site. J Biol Chem 1994;269:19457-61

Lee CC, Yamada K. Alternatively spliced juxtamembrane domain of a tyrosine kinase receptor is a multifunctional regulatory site. Deletion alters cellular tyrosine phosphorylation pattern and facilitates binding of phosphatidylinositol-3-OH kinase to the hepatocyte growth factor receptor. J Biol Chem 1995;270:507-10

Lee JH, Han SU, Cho H, Jennings B, Gerrard B, Dean M, Schmidt L, Zbar B, Vande Woude GF. A novel germ line juxtamembrane Met mutation in human gastric cancer. Oncogene 2000;19:4947-53

Lopez AJ. Alternative splicing of pre-mRNA: developmental consequences and mechanisms of regulation. Annu Rev
Genet 1998;32:279-305

Ma PC, Jagadeeswaran R, Jagadeesh S, Tretiakova MS, Nallasura V, Fox EA, Hansen M, Schaefer E, Naoki K, Lader A, Richards W, Sugarbaker D, husain AN, Christensen JG, Salgia R. Functional expression and mutations of c-Met and its therapeutic inhibition with SU11274 and small interfering RNA in non-small cell lung cancer. Cancer Res 2005;65: 1479-88

Montesano R, Schaller G, Orci L. Induction of epithelial tubular morphogenesis in vitro by fibroblast-derived soluble factors. Cell 1991;66:697-711

Nakamura T, Teramoto H, Ichihara A. Purification and characterization of a growth factor from rat platelets for mature parenchymal hepatocytes in primary cultures. Proc Natl Acad Sci USA 1986;83:6489-93

Naldini L, Weidner KM, Vigna E, Gaudino G, Bardelli A., Ponzetto C, Narsimhan RP, Hartmann G, Zarnegar R., Michalopoulos GK., Birchmeier W, Comoglio PM. Scatter factor and hepatocyte growth factor are indistinguishable ligands for the MET receptor. EMBO J 1991;10:2867-78

Nguyen L, Holgado-Madruga M, Maroun C, Fixman ED, Kamikura D, Fournier T, Charest A, Tremblay ML, Wong AJ, Park M. Association of the multisubstrate docking protein Gab1 with the hepatocyte growth factor receptor requires a functional Grb2 binding site involving tyrosine 1356. J Biol Chem 1997;272:20811-9

Otsuka T, Takayama H, Sharp R, Celli G, LaRochelle WJ, Bottaro DP, Ellmore N, Vieira W, Owens JW, Anver M, Merlino G. c-Met autocrine activation induces development of malignant melanoma and acquisition of the metastatic phenotype. Cancer Res 1998;58:5157-67

Park WS, Dong SM, Kim SY, Na EY, Shin MS, Pi JH, Kim BJ, Bae JH, Hong YK, Lee KS, Lee SH, Yoo NJ, Jang JJ, Pack S, Zhuang Z, Schmidt L, Zbar B, Lee JY. Somatic mutations in the kinase domain of the Met/hepatocyte growth factor receptor gene in childhood hepatocellular carcinomas. Cancer Res 1999;59:307-10

Peschard P, Fournier TM, Lamorte L, Naujokas MA, Band H, Langdon WY, Park M. Mutation of the C-CbI TKB domain binding site on the Met receptor tyrosine kinase converts it into a transforming protein. Mol Cell 2001;8:995-1004

Rong S, Segal S, Anver M, Resau JH, Vande Woude GF. Invasiveness and metastasis of NIH 3T3 cells induced by Met-hepatocyte growth factor/scatter factor autocrine stimulation. Proc Natl Acad Sci U S A 1994;91:4731-5

Schmidt L, Duh FM, Chen F, Kishida T, Glenn G, Choyke P, Scherer SW, Zhuang Z, Lubensky I, Dean M, Allikmets R, Chidambaram A, Bergerheim UR, Feltis JT, Casadevall C, Zamarron A, Bernues M, Richard S, Lips CJ, Walther MM, Tsui LC, Geil L, Orcutt ML, Stackhouse T, Lipan J, Slife L, Brauch $H$, Decker J, Niehans G, Hughson MD, Moch H, Storkel S, Lerman MI, Linehan WM, Zbar B. Germline and somatic mutations in the tyrosine kinase domain of the MET proto-oncogene in papillary renal carcinomas. Nat Genet 1997;16:68-73

Stoker M, Gherardi E, Perryman M, Gray J. Scatter factor is a fibroblast-derived modulator of epithelial cell mobility. Nature 
$1987 ; 327: 239-42$

Taher TE, Tjin EP, Beuling EA, Borst J, Spaargaren M, Pals ST. $\mathrm{c}-\mathrm{Cbl}$ is involved in Met signaling in B cells and mediates hepatocyte growth factor-induced receptor ubiquitination. J Immunol 2002;169:3793-800

Tanyi J, Tory K, Rigo J, Nagy B, Papp Z. Evaluation of the tyrosine kinase domain of the Met proto-oncogene in sporadic ovarian carcinomas. Pathol Oncol Res 1999;5:187-91

Trusolino L, Comoglio PM. Scatter-factor and semaphorin receptors: cell signalling for invasive growth. Nat Rev Cancer 2002;2:289-300
Tsarfaty I, Resau JH, Rulong S, Keydar I, Faletto DL, Vande Woude GF. The met proto-oncogene receptor and lumen formation. Science 1992;257:1258-61

Vigna E, Gramaglia D, Longati P, Bardelli A, Comoglio PM. Loss of the exon encoding the juxtamembrane domain is essential for the oncogenic activation of TPR-MET. Oncogene $1999 ; 18: 4275-81$

Villa-Moruzzi E, Puntonif F, Bardelli A, Vigna E, De Rosa S, Comoglio PM. Protein tyrosine phosphatase PTP-S binds to the juxtamembrane region of the hepatocyte growth factor receptor Met. Biochem J 1998;336:235-9 